\title{
Dynamics of Electromechanical Systems Containing Long Elastic Couplings and Safety of Their Operation
}

\author{
Andrzej Popenda $1, * \mathbb{C}$, Andrzej Szafraniec $2, * \mathbb{C}$ and Andriy Chaban ${ }^{2}$ \\ 1 Faculty of Electrical Engineering, Czestochowa University of Technology, 42-201 Czestochowa, Poland \\ 2 Faculty of Transport, Electrical Engineering and Computer Science, University of Technology and \\ Humanities, 26-600 Radom, Poland; atchaban@gmail.com \\ * Correspondence: andrzej.popenda@pcz.pl (A.P.); a.szafraniec@uthrad.pl (A.S.)
}

Citation: Popenda, A.; Szafraniec, A.; Chaban, A. Dynamics of

Electromechanical Systems Containing Long Elastic Couplings and Safety of Their Operation. Energies 2021, 14, 7882. https:// doi.org/10.3390/en14237882

Academic Editors: Sérgio Cruz and Ewa Korzeniewska

Received: 20 October 2021

Accepted: 19 November 2021

Published: 24 November 2021

Publisher's Note: MDPI stays neutral with regard to jurisdictional claims in published maps and institutional affiliations.

Copyright: (c) 2021 by the authors. Licensee MDPI, Basel, Switzerland. This article is an open access article distributed under the terms and conditions of the Creative Commons Attribution (CC BY) license (https:/ / creativecommons.org/licenses/by/ $4.0 /)$.

\begin{abstract}
The electromechanical systems under analysis include electric drives, working machines that perform specific tasks in the technological process, and working mechanisms that transmit mechanical power between the electric drive and the working machine. The vast majority of electric motors included in drive systems require rotational speed control. This task is most often performed with the use of closed-loop control structures based on speed controllers. A step or overly rapid change in the speed reference causes a temporary lock of the speed controller due to the applied limitations at its output. Particularly, unfavorable effects of such a lock can be observed in drive systems in which there is a long elastic coupling (transmission shaft) between the electric motor and the working machine. As a consequence, shaft torsion and accompanying twisting moments of considerable amplitudes appear. This article proposes an uncomplicated active torque limiter structure, which enables the uninterrupted operation of the speed controller thanks to the automatic adaptation of the rate of the speed reference change to any moment of inertia of the rotor and attached rotating masses. The results of the investigations confirm the effectiveness of the proposed structure.
\end{abstract}

Keywords: dynamics of electromechanical systems; vibration damping; transmission shaft; drive systems; induction motor; control strategies; rotational speed control; mathematical modeling

\section{Introduction}

Electric drives, being components of electromechanical systems, are used in all branches of industry and are the dominant recipient of electricity. For this reason, the failure-free operation of these systems is essential. The analysis of the operating states of drive systems is often associated with ensuring their operational safety. The key issue is to detect the occurrence of resonance and resonance-like phenomena, as they are most dangerous for the system. Dangerous phenomena include vibrations of considerable amplitude occurring in drive systems, especially in their working mechanisms, and these phenomena are caused by sudden changes in the driving torque or load torque. In such operating states, failures of mechanical elements occur most often. Failure to take into account these phenomena may damage the electric drives and sometimes stop production in the entire plant. One example is a complex drive system for electric submersible pumps powered by a soft starter [1]. In this case, an incorrect control strategy led to resonance and shaft failure. Therefore, comprehensive studies are needed to analyze the operating states of electrical and electromechanical systems.

In order to analyze the operating states of electrical and electromechanical systems, there is a need to conduct complex tests that are long and expensive. The solution to this problem is an analysis of the tested system presented in the form of a mathematical model. A mathematical model describes a physical object by a system of differential or algebraic equations or their combination. This description is more or less complex depending on the degree of accuracy in reproducing the processes taking place in the object under consideration. A mathematical model with lumped parameters describes an 
object with ordinary differential equations, while a mathematical model with distributed parameters describes an object with partial differential equations. Practice shows that, in order to obtain a high degree of representation of the physical phenomena occurring inside a tested device or a group of devices, the object should be analyzed as a system with distributed parameters [2-5].

Electric motors included in electric drives are coupled with working mechanisms via drive shafts, which are examples of mechanical power transmission. Mechanical power transmissions may be one-path or multi-path and may include gear trains and clutches [6]. Long drive shafts, defined as transmission shafts, are used primarily in drive systems in the steel industry, mainly in rolling mills [7,8] and paper machines [9]. In these applications, the length of the transmission shafts can exceed $10 \mathrm{~m}$, and their diameters can reach 0.5 to $0.8 \mathrm{~m}$. Transmission shafts are also used in drive systems of polymerization reactors. The length of these shafts ranges from 4 to $7 \mathrm{~m}$. Moreover, transmission shafts are used in hydro generator sets, drive systems of ships, submarines, etc. [10-12].

Depending on the length and cross section, transmission shafts may show different susceptibilities to the moment of torsion, the measure of which is the value of the angle of twist $[6,13]$. In the case of a short mechanical coupling, the value of the angle of twist is insignificant and may be neglected under the assumption of a rigid mechanical coupling, while this value cannot be omitted in the case of a longer mechanical coupling, and such coupling should be considered elastic [5,13-18].

Several researchers [19-24] have undertaken tests of stresses and vibrations of transmission shafts with the use of various methods of analysis, especially mathematical modeling. To model the transmission shafts, classical methods based on the d'Alembert principle and Newton's second law as well as the variational method are used. The variational method is based on a model with distributed parameters and consists of partial differential equations [13]. An example of a partial differential equation used to describe a long elastic element is the wave equation [25]. Partial differential equations can be solved analytically, but this is both tedious and time-consuming. Thus, these equations are usually converted into ordinary differential equations using finite differences [6]. Examples of models of long elastic elements based on ordinary differential equations include the multi-mass lumped parameter model presented in $[6,24,26]$ and the two-mass model presented, inter alia, in $[5,16,18,27,28]$, which do not guarantee accurate results in the numerical analysis. Equations describing a multi-mass model are usually solved by numerical integration.

Torsional vibrations not only strongly affect the operation of drive systems, but they also significantly complicate the analysis of the control system $[29,30]$. The task of the control system in such cases is to ensure that the speed of the drive system is achieved and maintained at a given level under various disturbances. Another task of the control system is to prevent mechanical oscillations in transient states, which can lead to the deterioration of the operating condition of the drive system. Therefore, the identification of the state of the mechanical system in electric drives is becoming an increasingly important problem [31,32].

In [33], an improved version of the adaptive nonlinear controller for a dual mass drive with nonlinear stiffness, damping, and friction with unknown parameters was proposed. The problem is complex and cannot be resolved with the standard backstepping approach. Therefore, several nonlinear control techniques were creatively used together to obtain a satisfactory result.

The papers [19,34] present the issues of modeling an elastic two-mass system and the damping residual vibrations therein.

It is estimated that over $75 \%$ of all electric motors installed in various types of equipment require speed control. This includes motors with additional angular position control. This applies not only to systems operating with an open-loop speed control, used e.g., in fan or pump drives, but also to complex closed-loop systems, e.g., used in servo drives and in driving lifting devices. 
Drive systems with an adjustable angular velocity appeared at the turn of the 20th centuries, along with the publication of the idea of adjusting the angular velocity of a DC motor by changing the armature voltage. Currently, drives with AC induction and synchronous motors excited by permanent magnets dominate. Synchronous motors are also the basis for the construction of drives with a brushless direct current (BLDC) motor. The BLDC motor drive is characterized by a simplicity of control; however, due to inferior dynamic properties and torque ripple, it is intended for applications where precise speed or position control is not required. The range of applications of alternating current machines includes, above all, high levels of power and rotational speed. Moreover, often where there are special requirements regarding operating conditions, e.g., an inflammable, corrosive, or dusty atmosphere, the use of AC motors is a must.

A step or overly rapid change in the speed reference for control systems of electric motors cause a temporary lock of the speed controller due to the applied limitations at its output. Particularly, the unfavorable effects of such a lock can be observed in drive systems where there is a long elastic coupling (transmission shaft) between the electric motor and the working machine $[5,6,13,17]$. As a consequence, shaft twists and accompanying torsional moments of considerable amplitudes appear. The necessity of using limiters at the output of speed controllers results from the need to limit the torque produced by the motor and the resulting overloads in the mechanical system, in addition to the current flowing in the circuits of the motor windings and the power electronic converter.

The aim of the research presented in this article is to analyze the behavior of an electromechanical system containing (a) a drive system consisting of an induction motor, a motor power supply system, and a vector control system, (b) a transmission shaft, and (c) a working machine, the role of which in the system under consideration is played by a DC brake generator. An additional aim is to propose a structure that prevents the speed controller from locking in all operating states of the drive system and thus contributes to the effective damping of vibrations arising in the working mechanism and to improve the safety of its operation.

The authors' own contribution is to identify the cause of the occurrence of weakly damped oscillations in the electromechanical system and to develop the structure of the module, which, when attached to a standard electric motor control structure, enables the uninterrupted operation of the speed controller and, consequently, the effective damping of oscillations in the mechanical system.

\section{Mathematical Model of an Electromechanical System Containing a Long Elastic Coupling}

\subsection{Mathematical Model of a Transmission Shaft}

In [21], the telegraphers' equations (System of Equation (1)) with boundary conditions (System of Equation (2)) and their solution (Equations (3) and (4)), defined by d'Alembert, were proposed for a mathematical description of the transmission shaft:

$$
\begin{gathered}
-\frac{\partial^{2} M}{\partial x^{2}}=\frac{1}{v^{2}} \frac{\partial^{2} M}{\partial t^{2}} ;-\frac{\partial^{2} \omega}{\partial x^{2}}=\frac{1}{v^{2}} \frac{\partial^{2} \omega}{\partial t^{2}} ; v=\frac{1}{\sqrt{J^{\prime} S^{\prime}}}=\sqrt{\frac{G}{\rho}}, \\
\left.M(x, t)\right|_{x=0}=M_{1}(t) ;\left.\quad \frac{\partial M(x, t)}{\partial x}\right|_{x=0}=-J^{\prime} \frac{\partial \omega_{1}(t)}{\partial t}, \\
M_{1}(t)=z_{v} \omega_{1}(t)-z_{v} \omega_{m}\left(t-\frac{l}{v}\right)+M_{m}\left(t-\frac{l}{v}\right), \\
M_{m}(t)=-z_{v} \omega_{m}(t)+z_{v} \omega_{1}\left(t-\frac{l}{v}\right)+M_{1}\left(t-\frac{l}{v}\right),
\end{gathered}
$$


where $v$ is the phase velocity given in $\mathrm{m} / \mathrm{s}, J^{\prime}$ and $S^{\prime}{ }_{c}$ are the linear densities (with respect to the length unit) of the moment of inertia and the torsional susceptibility coefficient, $S^{\prime}{ }_{c}=\rho / G J^{\prime}, \rho$ is the mass density given in $\mathrm{kg} / \mathrm{m}^{3}, G$ is the shear modulus given in GPa, $M_{1}$ and $M_{m}$ are the moments of torsion at the beginning and at the end of the shaft, respectively, $\omega_{1}$ and $\omega_{m}$ are the angular velocities at the beginning and end of the shaft, $z_{v}$ is the wave impedance, $z_{v}=\sqrt{J^{\prime} / S^{\prime}{ }_{c}}=v J^{\prime}$, and $l$ is the shaft length. The abovementioned moments of torsion can also be presented in a discrete form:

$$
\begin{gathered}
M_{1}(j)=z_{v} \omega_{1}(j)-z_{v} \omega_{m}(j-n)+M_{m}(j-n), \\
M_{m}(j)=-z_{v} \omega_{m}(j)+z_{v} \omega_{1}(j-n)+M_{1}(j-n),
\end{gathered}
$$

with predetermined initial conditions $M_{1}(0), M_{m}(0), \omega_{1}(0)$, and $\omega_{m}(0)$, where $n$ is the number of modeling steps, which is a number that expresses the time of the passage of the mechanical wave through the shaft, $n=l / v h, h$ is the width of the modeling step size, $j=0,1, \ldots$ The time of the passage of the mechanical wave through the shaft, corresponding to the number $n$, is given as $l / v$ in Equations (3) and (4).

The angular velocities at the beginning and end of the shaft can be calculated from the equations of motion for the electric motor and the working machine:

$$
\begin{gathered}
J_{e} \frac{d}{d t} \omega_{1}(t)=M_{e}(t)-D_{1} \omega_{1}(t)-D_{1 m}\left(\omega_{1}(t)-\omega_{m}(t)\right)-M_{1}(t), \\
J_{L} \frac{d}{d t} \omega_{m}(t)=M_{m}(t)-D_{m} \omega_{m}(t)-D_{m 1}\left(\omega_{m}(t)-\omega_{1}(t)\right)-M_{L}(t),
\end{gathered}
$$

where $M_{e}(t)$ and $M_{L}(t)$ are the air-gap torque of the electric motor and the load torque of the working machine given in $\mathrm{N} \cdot \mathrm{m}, J_{e}$ and $J_{L}$ are the moments of rotor inertia for the electric motor and the working machine given in $\mathrm{kg} \cdot \mathrm{m}^{2}$, and $D_{1}$ and $D_{m}$ are the coefficients of friction in the bearings. In order to take into account the viscous friction inside the shaft, the components $D_{1 m}\left(\omega_{1}(t)-\omega_{m}(t)\right)$ and $D_{m 1}\left(\omega_{m}(t)-\omega_{1}(t)\right)$ with lumped parameters $D_{1 m}$ and $D_{m 1}$ are introduced into Equations (7) and (8).

The assumptions for the model are as follows. System of Equation (1), which was used for the mathematical description of the transmission shaft under the boundary conditions (System of Equation (2)), was derived under the assumption that the shaft is homogeneous; i.e., the parameters along the shaft axis do not change. Moreover, the losses related to the viscous friction inside the shaft were omitted in the aforementioned equations in order to use the solution given by d'Alembert (Equations (3) and (4)). These losses have been taken into account alternatively by introducing additional terms into Equations (7) and (8). If the shaft is part of a complex system, then we can limit ourselves only to the quantities occurring at its boundaries, without the need to reproduce the phenomena for any point along the shaft axis. In this case, in Equations (3) and (4), there are only two values of the shaft length coordinate $x$ : 0 (shaft beginning) and $l$ (shaft end). This assumption leads to very simple equations of the discrete model (Equations (5) and (6)) of the lossless transmission shaft.

The proposed model of the transmission shaft is an alternative to the multi-mass model based on ordinary differential equations as well as to the model with distributed parameters based on partial differential equations. The advantage of the proposed model is its simplicity, as it is based on discrete algebraic equations that do not require numerical integration, unlike models based on differential equations. The proposed model of the transmission shaft has been verified experimentally using the laboratory stand shown in Figure 1.

The length and diameter of the shaft in the experimental system were designed adequately to the power of the components of the experimental system. The configuration of the experimental system allows for the use of shafts of different diameters, which allows for a good representation of the parameters of real systems in which the length of 
transmission shafts can reach over $10 \mathrm{~m}$, and the power of electric drives can be several hundred or even several thousand kilowatts.

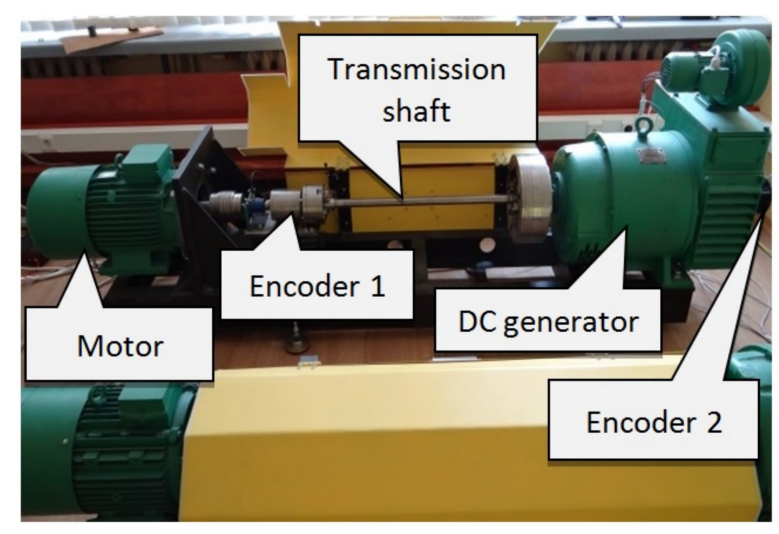

Figure 1. Stand for testing a drive system with elastic coupling.

Table 1 presents the specification of the components of the test stand for the drive system with elastic coupling shown in Figure 1.

Table 1. Specification of the components of the stand presented in Figure 1.

\begin{tabular}{cc}
\hline Component of the Stand & Parameters \\
\hline Brushless DC motor PMSg 132 S4 from Komel & rated power: $4.0 \mathrm{~kW}$ \\
& rated voltage: $400 \mathrm{~V}$ \\
& rated current: $11.5 \mathrm{~A}$ \\
& rated speed: $1500 \mathrm{rpm}$ \\
\hline DC generator PKMa44a/117 from Elmor & rated power: $4.6 \mathrm{~kW}$ \\
& rated voltage: $230 \mathrm{~V}$ \\
& rated current: $20 \mathrm{~A}$ \\
rated speed: $1450 \mathrm{rpm}$ \\
\hline Incremental encoder Sendix 5000 from Kuebler & supply voltage: $5-24 \mathrm{~V} \mathrm{DC}$ \\
& resolution: $3600 \mathrm{ppr}$ \\
& interfaces: $\mathrm{RS} 422$ \\
& switching frequency: $300 \mathrm{kHz}$ \\
\hline Steel shaft & length: $66 \mathrm{~mm}$ \\
& diameter: $8 \mathrm{~mm}$ \\
& mass density: $7900 \mathrm{~kg} / \mathrm{m} 3$ \\
& shear module: $77.5 \mathrm{GPa}$ \\
& wave impedance: $0.01 \mathrm{Nms}$ \\
phase velocity: $3132 \mathrm{~m} / \mathrm{s}$
\end{tabular}

The test stand, shown in Figure 1, is fully configurable, thanks to which it is possible to mount additional steel discs on the shaft on the DC generator side, which allows the moment of load inertia to be changed. The angular displacements and velocities are measured by two rotary incremental encoders with a resolution of $3600 \mathrm{pulse} / \mathrm{rev}$. These encoders are installed at the ends of the transmission shaft. HAS 50-S hall effect transducers from LEM are used to measure the motor phase currents. The measurement signals from the transducers are sent to a laboratory computer equipped with two multifunctional I/O devices.

At the stand for testing the electromechanical system containing the transmission shaft (Figure 1), a brushless DC motor, powered from a factory converter equipped with a closed-loop control system, was used. The control task was performed using a standard cascade structure with closed loops: outer for controlling the motor speed and inner for controlling the motor torque or current. 
The presented waveforms were acquired by starting the motor and operation under a rated load after $5.5 \mathrm{~s}$. Figure 2 shows the angular velocity at the beginning of the shaft obtained by computer simulation and by measuring in the test stand.

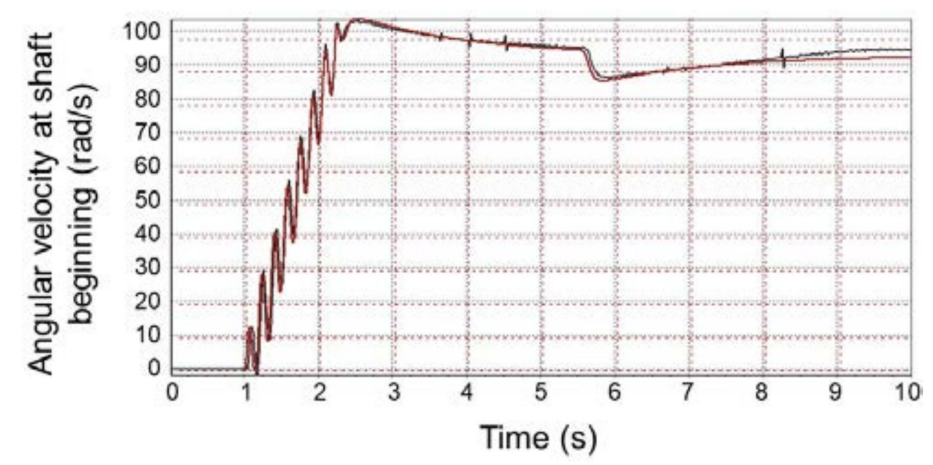

Figure 2. Comparison of the results of simulation tests (brown line) and experimental tests (black line) for the angular velocity at the beginning of the shaft [21].

The presented waveforms show the lock of the speed controller when starting the motor, manifested by weakly damped oscillations of mechanical quantities with significant amplitudes, as well as the high efficiency of damping these oscillations after unlocking the speed controller from about $2.3 \mathrm{~s}$. It was possible to determine this lock as a result of the modeling and simulation studies carried out. The high similarity of the simulation and experimental results confirms the adequacy of the proposed model.

Both waveforms presented in Figure 2 show a high similarity of the obtained results. Noise caused by disturbances in the measuring system is visible in the measured waveform. In the waveforms, during the increase in angular velocity, i.e., when starting the motor, the oscillating nature of these waveforms is clearly visible. On the other hand, after the motor reaches the speed close to the speed reference, i.e., after about $1.3 \mathrm{~s}$ from the initiation of the motor start-up, these oscillations disappear immediately.

Figure 3 shows the waveforms of the angle of the shaft twist, which largely reflects the moment of torsion.

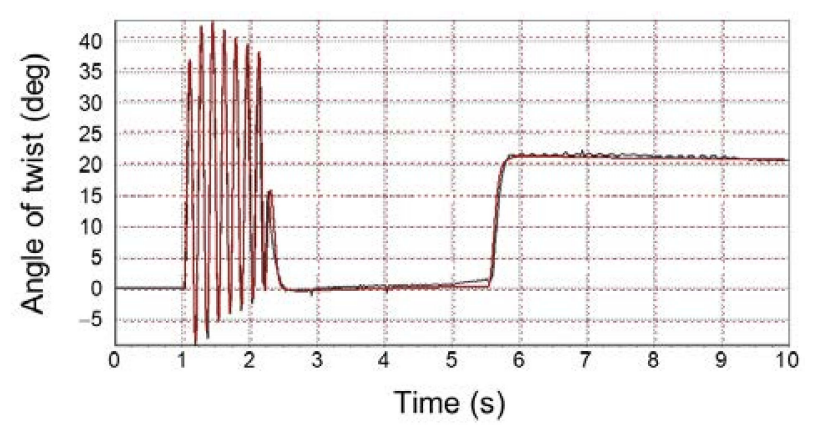

Figure 3. Comparison of the results of simulation tests (brown line) and experimental tests (black line) for the angle of the shaft twist [21].

The choice of the angle of twist for the presentation is a result of the possibility of direct measurements of the angles of rotation on both sides of the shaft with the use of the installed encoders and the calculation of the angle of twist as their difference, while in the case of measuring the moment of torsion, there is a problem with the accuracy of such measurements, especially in the transient states. The observed differences in the simulation results and the experimental tests are due mainly to differences in the parameters of the speed controller (the authors were not aware of the parameters of the speed controller used in the factory converter supplying the motor). However, there are no major differences in the dynamic behavior of the electromechanical system. 
The waveforms of the angle of the shaft twist during motor start-up presented in Figure 3 show an oscillation of considerable amplitude that immediately disappears after the end of the start-up. In these graphs, it can also be observed that the rapid change in the load torque from $5.5 \mathrm{~s}$ does not have an oscillating effect.

\subsection{Mathematical Model of an Induction Motor}

The analysis of static and dynamic phenomena occurring during motor operation is necessary both at the design stage and during the operation of drive systems. Carrying out such an analysis requires the development of mathematical models of the tested motors. Circuit models are the basis for the mathematical description of drive systems, including automated converter-fed motor systems used in numerous technological processes.

In the case of circuit modeling, the task is reduced to solving two basic problems: (a) formulating a system of differential equations and (b) determining the values of the coefficients (parameters) appearing in these equations. A well-carried out model parameter estimation of the selected object is the key to its diagnostics and simulation. If the selection of the model and estimation methods are appropriate for a given object, then this solution can be duplicated, and satisfactory results can be obtained in terms of the simulation or diagnostics of the object under consideration.

For mathematical descriptions of induction machines, usually, equations written with the use of space vectors, which formulate the vector form of the circuit model, are used. The vector form of a circuit model is obtained after applying the definition of a space vector to the equations of the voltage balance for the stator and rotor circuits of a three-phase induction machine. As a result of this transformation, voltage equations containing vector variables represented on the plane of complex variables or after transformation to the matrix form, variables represented in the Cartesian coordinate system are obtained.

The space vector definition is based on the assumption that a symmetrical three-phase system of quantities, represented in natural coordinates (denoted as $a, b, c$ or $u, v, w$ ) by phase values (e.g., voltages, currents, and fluxes), can be replaced by one rotating or stationary space vector (of the voltage, current, or flux, respectively), associated with an orthogonal or polar coordinate system, while the coordinate systems can be stationary, i.e., naturally associated with the stator, or rotating, e.g., with the rotor.

In [35], a mathematical model of an induction motor, taking into account the skin effect in the rotor cage bars by varying the rotor resistance and leakage reactance, was proposed. The model formula was based on the voltage equations of an induction machine written with the use of space vectors, related to the coordinate system rotating at any speed $\omega_{a}$ :

$$
u_{s}=R_{s} i+\frac{d}{d t} \psi_{s}+j \omega_{a} \psi_{s} ; u_{r}=R_{r} i_{r}+\frac{d}{d t} \psi_{r}+j\left(\omega_{a}-p_{b} \omega_{m}\right) \psi_{r},
$$

where $\underline{u}_{s}, \underline{u}_{r}, \underline{\psi}_{s}, \underline{\psi}_{r}, \underline{i}_{s}$, and $\underline{i}_{r}$ are space vectors of voltages, flux linkages, and currents of the stator and rotor, respectively, $R_{s}$ and $R_{r}$ are the resistances of the stator and rotor windings, $\omega_{m}$ is the rotor angular velocity, and $p_{b}$ is the number of pole pairs. System of Equation (9) is completed with the flux-current dependencies (System of Equation (10)) and the equation of the rotor motion (Equation (11)):

$$
\begin{gathered}
\psi_{s}=L_{\sigma s} i_{s}+L_{m}\left(\begin{array}{c}
i+i_{r} \\
i_{r}
\end{array}\right) \psi_{r}=L_{\sigma r} i_{r}+L_{m}\left(\begin{array}{c}
i \\
s
\end{array}\right), \\
J_{m} \frac{d}{d t} \omega_{m}=m_{e}-m_{m} ; \quad m_{e}=p_{b} \operatorname{Im}\left(\psi_{s}^{*} \cdot i_{s}\right),
\end{gathered}
$$

where $L_{\sigma S}, L_{\sigma r}$, and $L_{m}$ are the leakage inductances of the stator and rotor windings and the magnetization inductance, $J_{m}$ is the moment of rotor inertia, $m_{e}$ is the air-gap torque of the motor, $m_{m}$ is the sum of the load torque of the working machine (external load) and the torque of mechanical losses of the motor (internal load). The air-gap torque or 
electromagnetic torque of an induction motor is the torque produced by the rotor current obtained by the electromagnetic induction from the magnetic field of the stator winding.

With the high slip of the rotor of the squirrel cage induction motor, occurring, e.g., during direct start-up, there is a one-sided displacement of the current in the cage bars, related to the skin effect. Taking into account the skin effect in the rotor cage bars is intended to improve the accuracy of the mathematical modeling and the obtained simulation results in relation to the measurement results and is particularly important in deep-bar and multicage squirrel-cage induction motors. For this purpose, variable parameters of the rotor winding were used in Equations (9) and (10):

$$
R_{r}=R_{r n} \frac{S_{p}}{\sigma b_{r 1}} \approx R_{r n} \frac{h_{r}}{\sigma}=k_{r} R_{r n} ; \quad L_{\sigma r} \approx \frac{L_{\sigma r n}}{k_{r}},
$$

where $R_{r n}$ and $L_{\sigma r n}$ are the resistance and leakage inductance of the squirrel cage winding without a skin effect, $S_{p}$ is the cross-section area of the bar, $b_{r 1}$ is the rotor slot width approximately equal to the bar width, and $h_{r}$ is the bar height.

The depth $\sigma$ of the current penetration into the cage bar, measured from the outer part of the bar, determines the active cross-sectional area of the bar through which the current passes for a given frequency $f_{2}$, so the rotor resistance depends on $\sigma$. The depth of penetration (magnetic diffusion depth) is determined by solving the magnetic diffusion equation, which, for a quasi-static magnetic field or at low frequencies of the flowing current, describes the penetration of the magnetic field into the conductor, as well as the alternating current distribution in the conductor. The magnetic diffusion equation is derived using the laws of Faraday, Ampere, and Gauss, where, in the case under consideration, (a) a one-dimensional case is assumed (a cage bar without skew, a conducting current in the direction of the rotor shaft axis), (b) the magnetic field acts in the direction of the developed rotor circumference and depends only on the coordinate measured in the direction of the bar height with a negligible edge effect, and (c) the reference frame is associated with the rotor (the rotor is stationary with respect to this frame). The depth $\sigma$ of the current penetration into the cage bar, measured from the outer part of the bar is given as follows:

$$
\sigma=\sqrt{\frac{2 \rho}{\omega \mu}}=\frac{1}{2 \pi} \sqrt{\frac{10^{7} \rho}{\mu_{r} f_{2}}},
$$

where $f_{2}$ is the frequency of the rotor current, $\rho$ is the conductor resistivity, and $\mu$ is the magnetic permeability. Thus, the variable $k_{r}$ in the dependencies (12) is a function of the square root of the flowing current frequency, which can be expressed as follows:

$$
k_{r}=\sqrt{\frac{f_{2}}{f_{2 g r}}}
$$

where $f_{2 g r}$ is the frequency at which the depth of penetration of the current is equal to the height of the bar.

In order to check the correctness of the applied induction motor mathematical model, an experimental verification of the obtained simulation results was carried out. Measurements during the direct starting of the motor were made with the use of an electromechanical unit, which included a squirrel-cage induction motor with the following parameters: a rated power of $4 \mathrm{~kW}$, a rated voltage and rated current of $400 \mathrm{~V}$ and $8 \mathrm{~A}$, respectively, at the star connection of the stator winding, and a power factor of 0.86 . The motor was connected directly to the rated voltage grid, and the waveforms of the phase current and phase voltage as well as the instantaneous power calculated for one phase of the motor on the basis of the measured values of voltage and current were recorded.

A comparison of the measured and simulated motor phase current waveforms during start-up is shown in Figure 4, where the red lines show the phase current after filtering the fundamental frequency component using a FFT low-pass filter of $14 \mathrm{~Hz}$. 


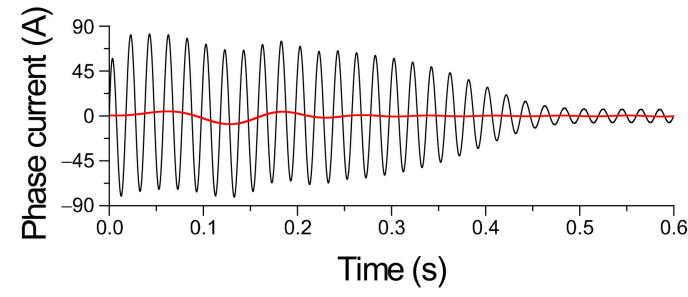

(a)

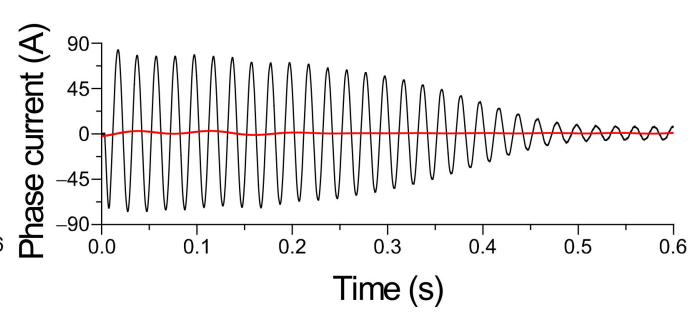

(b)

Figure 4. Motor phase current waveforms during start-up: (a) simulated; (b) measured.

In the waveforms of the phase currents obtained both by computer simulation and by measurement, the presence of a low-frequency component (red line) can be observed, although it has a lower amplitude in the case of the measurement. Both waveforms show a comparable start-up time and a comparable current amplitude during and after starting the motor.

A comparison of the waveforms of the measured and simulated instantaneous power for one motor phase during start-up is shown in Figure 5, where the red lines show the instantaneous power after filtering the component with double the fundamental frequency using a FFT low-pass filter of $50 \mathrm{~Hz}$.

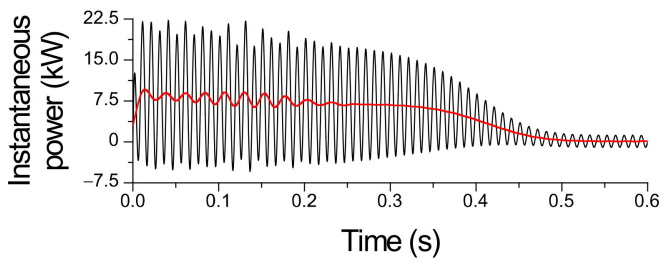

(a)

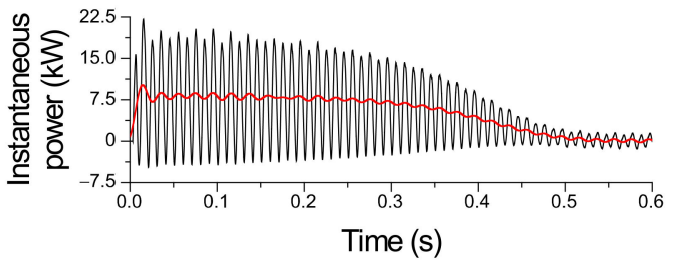

(b)

Figure 5. Waveforms of single phase instantaneous power during motor start-up: (a) simulated; (b) measured.

As in the case of currents, the presence of a low-frequency component (red line) can be found in the waveforms of instantaneous power, simulated and calculated on the basis of the currents and voltages measured. However, in the case of instantaneous power, the low-frequency component is modulated by the low-frequency component present in the motor phase current waveforms.

Based on the comparison of the results of the simulation and experimental tests, it can be concluded that the adequacy of the applied mathematical model of the induction motor is satisfactory. The advantage of modelling and simulation studies is the possibility of obtaining information on quantities that are difficult to measure or are inaccessible, e.g., magnetic fluxes, electromagnetic torque, and the angular velocity and angular position of the rotor. By comparing the results of the computer simulation with the results of measurements in terms of the quantities available for measurement and by stating their similarity, it is possible to evaluate the adequacy of the mathematical model used and the analogous similarity of the quantities that are difficult or impossible to measure. As a standard, readily available measurement values include currents and voltages, i.e., electrical quantities.

\section{The Control Structure of an Induction Motor}

The speed control systems of induction motors are largely based on frequency techniques. There are two basic techniques for the frequency control of induction motor angular velocity or rotational speed: scalar control and vector control. Scalar control techniques are used primarily in drive systems with medium dynamic requirements. In this group, the most popular on the market is a drive system with a squirrel-cage induction motor, powered by a transistor voltage inverter and controlled according to the principle of a 
constant ratio of supply voltage or induced voltage to frequency, varying from 0 to the rated value. The idea behind this method is to keep the magnetic flux in the air-gap of the motor approximately constant. Such systems are characterized by good mechanical dynamics. In applications where the quality of control is determined by the requirements of the technological process or product, vector control methods are used, and they include two basic strategies: field-oriented control and direct torque control.

Figure 6 shows a block diagram of the speed control system of an induction motor (AC motor), based on the torque and flux control [36].

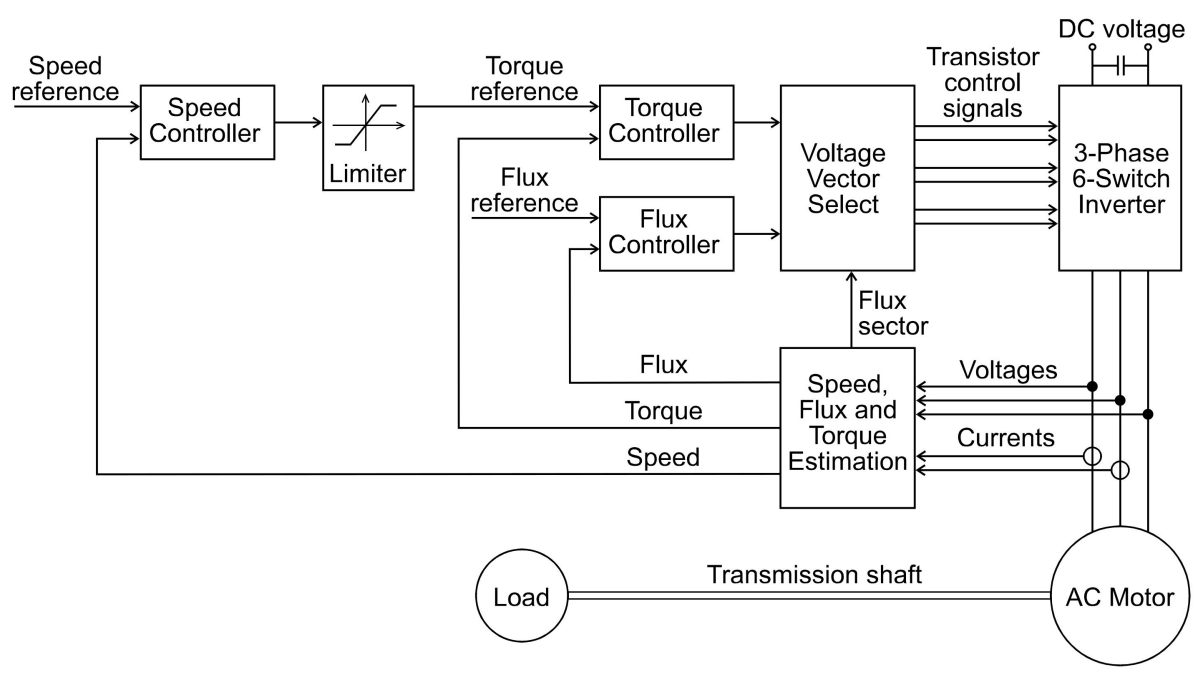

Figure 6. Block diagram of the speed control system of an induction motor containing a long elastic coupling (transmission shaft).

This closed-loop control strategy is designed to control the torque, flux, and rotational speed of an induction motor. The loops include an inner-loop three-state torque controller, a two-state (bang-bang) flux controller, and a linear outer-loop PI controller used to control the rotational speed of an induction motor in a cascade control system.

Analogous solutions in the speed control path are being used in the case of brushed and brushless DC motors, which alternatively have closed loops for controlling motor torque or armature current, similarly to the field-oriented control of an induction motor. Measurements of line-to-line voltages in the considered system (Figure 6) can be replaced by measurements of the DC voltage in the intermediate circuit of the frequency converter, supplying the motor and the reading of the angular position of the motor (inverter) voltage vector from the voltage vector selection table.

The torque reference limiter used in the system causes a temporary lock of the speed controller given an overly rapid change in the speed reference. Disabling the closed-loop speed control results in the appearance of poorly damped oscillations, especially visible in the working mechanism. The immediate cause of the oscillating effect is a rapid change in the torque produced by the drive motor with a simultaneous lack of oscillation damping caused by locking the speed controller. This applies to various systems equipped with closed-loop speed control, including systems with DC motors, as shown by the waveforms presented in Figures 2 and 3. The same waveforms also show that the oscillating effect does not occur in the case of a sudden change in load torque produced by the working machine, as it is not accompanied by a speed controller lock. The solution to the problem of vibration damping in all operating states of the drive system, as well as during start-up and reversal, i.e., in the states when the speed controller is locked as a result of a limitation at its output, is a slowdown of the rate of the speed reference change. The intensity of this slowdown should be adapted to the actual moment of the inertia of the electric motor rotor and the associated rotating masses. In more complex working mechanisms, it is connected to the necessity to determine the equivalent moment of inertia, considered in terms of the motor shaft. 
Figure 7 shows the speed control system for an induction motor based on the structure shown in Figure 6 with an active torque limiter attached.

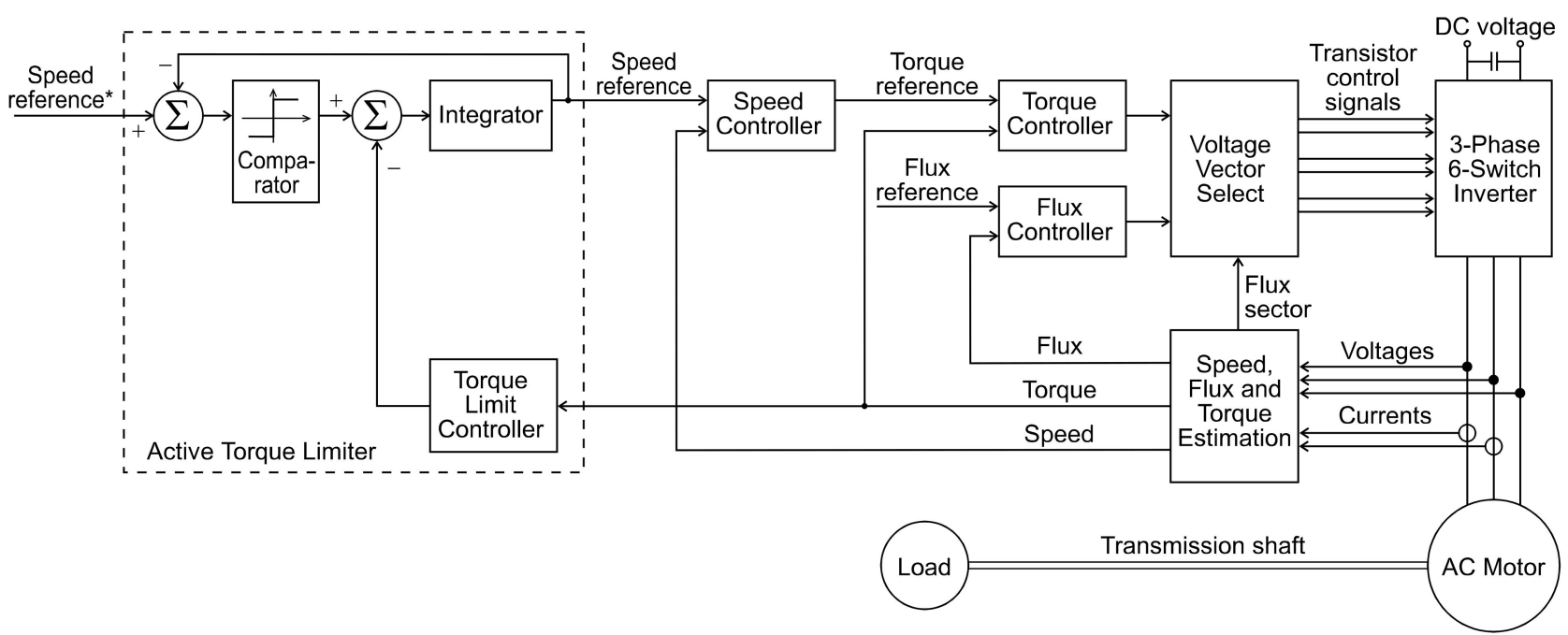

Figure 7. Block diagram of the speed control system for an induction motor, equipped with an active torque limiter.

The proposed structure enables the uninterrupted operation of the speed controller thanks to the automatic adaptation of the rate of the speed reference change to any moment of inertia. A static structure was used as a torque limit controller because the phase shifts caused by astatic controllers adversely affect the oscillation damping process. Two cases of a static controller were considered, i.e., linear and non-linear, wherein the functions of the first and fifth power of the motor torque were used, respectively. In both cases, the controller coefficients were experimentally adjusted to obtain the desired level of torque limitation.

In the current research, the authors limited themselves to examining the control system equipped with a PI controller with a basic structure, thus focusing on examining the influence of the proposed active torque limiter. In future research, how the proposed active torque limiter works with a controller equipped with an anti-windup filter will be studied.

\section{The Results of Investigations}

To verify the proposed solutions, simulation investigations were performed. The algorithm computer program in the $\mathrm{C}++$ programming language was written by the research team. Open and free software was used to write the simulation program. The independent development of a simulation program enables optimization of the algorithm code, which in the future may be implemented in an inverter with a digital signal processor.

The tested drive system consists of an induction motor with a power of $4 \mathrm{~kW}$ coupled with a DC brake generator via a steel drive shaft $0.66 \mathrm{~m}$ long and $8 \mathrm{~mm}$ in diameter. A steel disc is installed on the DC generator side, which acts as an additional rotating mass. The moment of inertia of the total mass containing the rotor of the DC generator and the disc installed at the end of the shaft is $0.17 \mathrm{~kg} \cdot \mathrm{m}^{2}$, while the moment of inertia of the total mass containing the rotor of the induction motor and the clutch is $0.042 \mathrm{~kg} \cdot \mathrm{m}^{2}$.

Figure 8 shows examples of the waveforms of the air-gap torque of the induction motor (a) and the torque at the point of connection of the induction motor with the transmission shaft (b) in the tested drive system with the basic control structure (Figure 6), when starting the motor. The torque at the point of connection of the induction motor with the transmission shaft is described in the graphs as "torque at shaft beginning". The torque at the beginning of the shaft is equal to the moment of torsion, while its waveform largely reflects the waveform of the angle of the shaft twist. The control system uses the limitation of the torque reference at the speed controller output to 1.57 of the motor's rated torque. The speed controller coefficients were adjusted experimentally. 


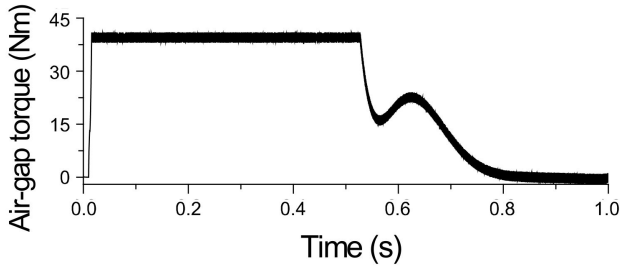

(a)

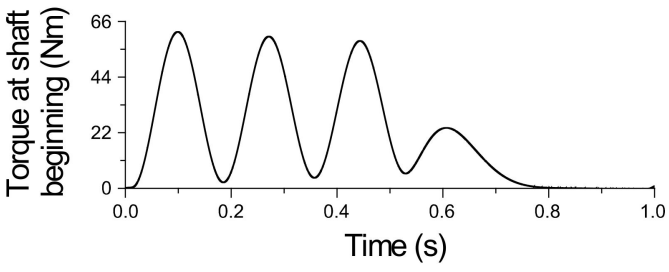

(b)

Figure 8. Waveforms of the air-gap torque of an induction motor (a) and the torque at the point of connection of the induction motor with the transmission shaft $(\mathbf{b})$ when starting the motor in the drive system shown in 0.

The lock of the speed controller is clearly visible for approximately half a second from the initiation of motor start-up. During this time, the signal at the speed controller output equal to the torque reference reaches a constant limit (saturation), which is visible in the air-gap torque waveform (Figure 8a). Although the air-gap torque remains constant at the limit value, the torque at the shaft beginning oscillates with considerable amplitude because there is no damping from the locked speed control loop. These oscillations occur as a result of a sharp change in the air-gap torque produced by the motor at the initial stage of the start-up.

Figure 9 shows the waveforms of the same quantities as in Figure 8, but during the motor reversal.

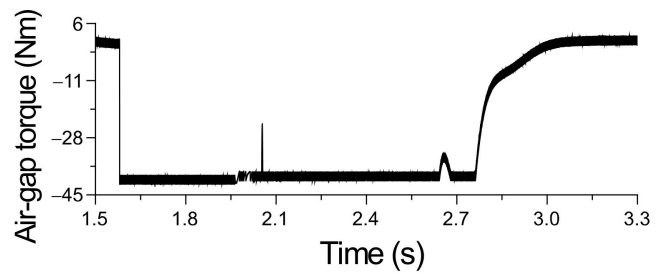

(a)

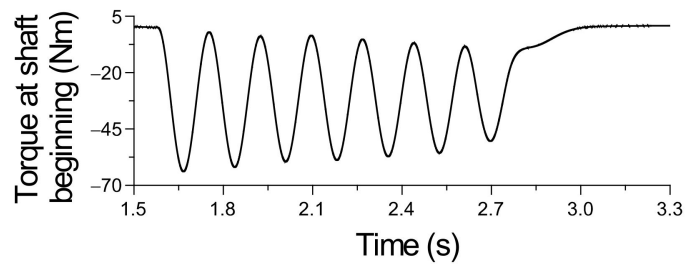

(b)

Figure 9. Waveforms of the air-gap torque of an induction motor (a) and the torque at the point of connection of the induction motor with the transmission shaft $(\mathbf{b})$ during the motor reversal in the drive system shown in Figure 6.

The lock of the speed controller is also visible for approximately $1.2 \mathrm{~s}$ from the initiation of the motor reversal, in the time interval $1.6 \mathrm{~s}<\mathrm{t}<2.8 \mathrm{~s}$. During this time, the air-gap torque reaches the negative level of the torque reference limit, and, in the waveform of the torque at the beginning of the shaft, weakly damped oscillations of considerable amplitude occur. On the other hand, when the speed controller leaves the limitation zone, oscillations are quickly damped as a result of unlocking it. Moreover, the unlocked speed controller copes with the task of damping oscillations effectively without the use of any additional damping loops or devices.

The oscillating character is also shown by the angular velocity of the motor during motor start-up (a) and motor reversal (b), followed by an immediate damping effect after the end of each of the two abovementioned processes, as shown in Figure 10. The angular velocity at the point of connection of the induction motor with the transmission shaft is described in the graphs as the "angular velocity of motor".

Figures 11-13 show examples of air-gap torque waveforms of an induction motor as well as the torque and angular velocity at the point of the connection of the induction motor to the transmission shaft in the tested drive system equipped with an active torque limiter (Figure 7) during motor start-up and reversal. The abovementioned figures show a comparison of the relevant quantities when two types of torque limit controller are used, i.e., linear and non-linear. As in Figures 8-10, the torque and angular velocity at the point of connection of the induction motor to the transmission shaft are described in the graphs as "torque at shaft beginning" and "angular velocity of motor", respectively. The moment of inertia of the total mass containing the rotor of the DC generator and the disc installed at 
the end of the shaft is $0.17 \mathrm{~kg} \cdot \mathrm{m}^{2}$. In the tested system, a step change of the speed reference was forced at the input of the active torque limiter.

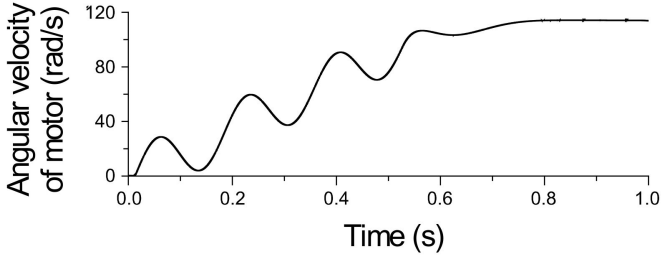

(a)

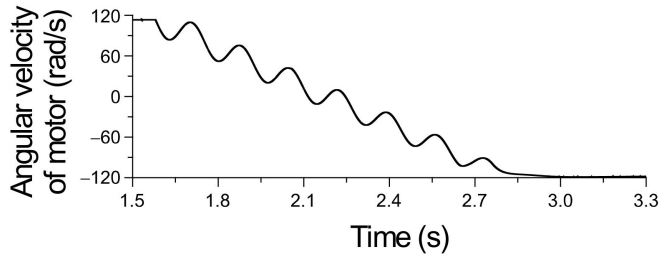

(b)

Figure 10. Waveforms of angular velocity during motor start-up (a) and motor reversal (b) in the drive system shown in Figure 6.

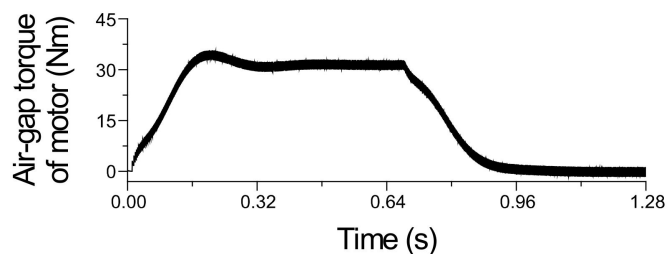

(a)

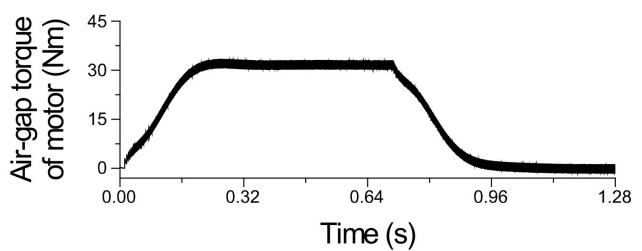

(b)

Figure 11. The waveforms of the air-gap torque of an induction motor in the control system shown in Figure 7 with a linear (a) and non-linear (b) torque limit controller during motor start-up.

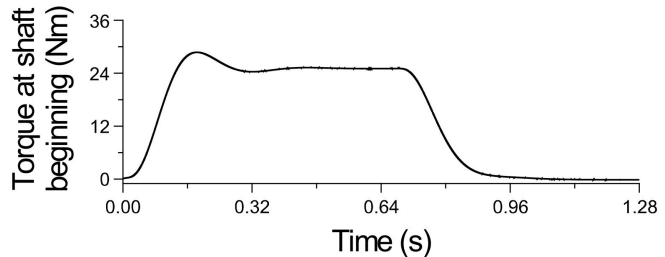

(a)

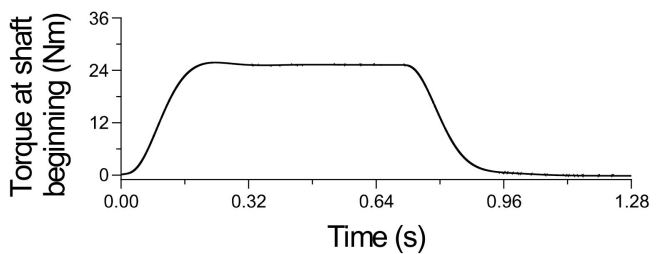

(b)

Figure 12. Waveforms of the torque at the beginning of the transmission shaft in the control system shown in Figure 7 with a linear (a) and non-linear (b) torque limit controller during motor start-up.

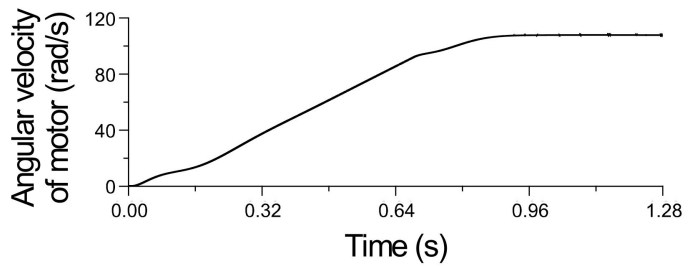

(a)

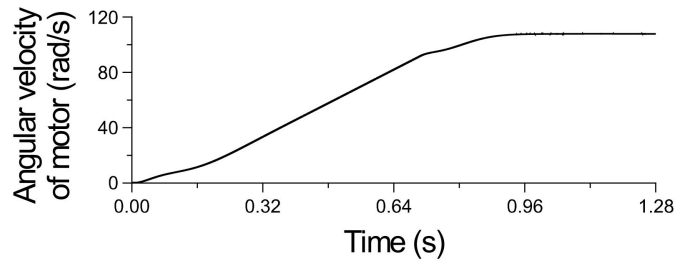

(b)

Figure 13. Waveforms of the angular velocity of the motor in the control system shown in Figure 7 with a linear (a) and non-linear (b) torque limit controller during motor start-up.

In the case of the basic control structure in Figure 6, the air-gap torque of the motor changes rapidly at the initiation of the motor start-up and remains constant due to the signal limitation at the speed controller output during that start-up (Figure 8a). In the case of the structure with an active torque limiter, shown in Figure 7, changes in the air-gap torque of the motor result from the operation of a non-locked speed controller and force damping oscillations in the mechanical system (Figure 11).

Comparing the (a) and (b) waveforms in Figures 11 and 12, it is possible to find a more favorable operation of the non-linear torque limit controller due to smaller overshoots 
appearing in the torque waveforms. On the basis of additional studies, not presented in the article, it is also possible to find a smaller differentiation of the levels of torque limitation for various values of the moments of inertia in the working mechanism in the case of the non-linear controller. Therefore, further results apply to a system with a non-linear torque limit controller.

Figure 14 shows the waveforms of the torque at the beginning of the transmission shaft and the angular velocity of the motor in the control system from Figure 7 during the motor's reversal. The parameters of the mechanical system during the reversal of the motor are the same as during the start-up, described above Figure 11.

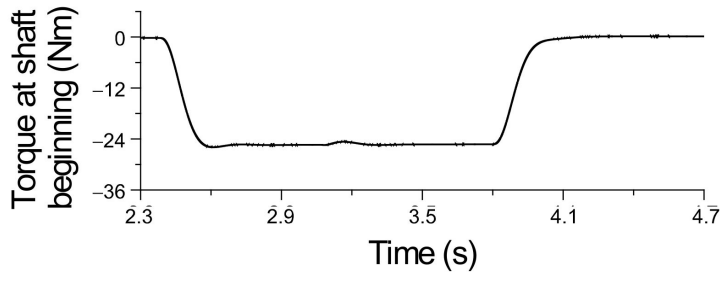

(a)

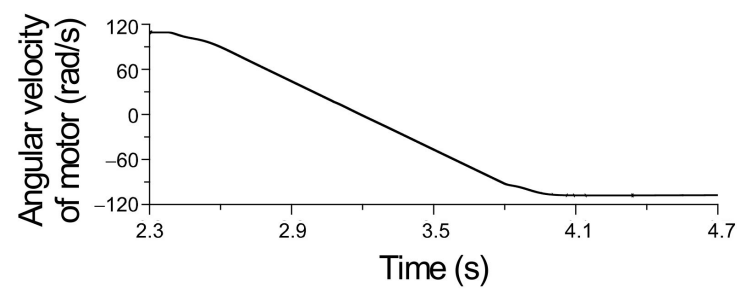

(b)

Figure 14. Waveforms of the torque at the beginning of the transmission shaft (a) and the angular velocity of the motor (b) during the motor reversal in the control system shown in Figure 7 after a step change of the speed reference* at the input of the active torque limiter.

In the case of motor reversal, the analyzed system has non-oscillating properties, as shown in Figure 14.

Subsequent studies concern the behavior of the considered system for different moments of inertia of the total mass containing the rotor of the DC generator and the disc installed at the end of the shaft. The following moments of inertia mentioned above were considered: $0.056 \mathrm{~kg} \cdot \mathrm{m}^{2}$ and $1 \mathrm{~kg} \cdot \mathrm{m}^{2}$, respectively. Figure 15 shows the waveforms of the air-gap torque (a) and the torque at the beginning of the shaft (b), while Figure 16 shows the waveforms of the angular velocity reference (a) and the angular velocity of the motor (b) during motor start-up in the system shown in Figure 7 for the $0.056 \mathrm{~kg} \cdot \mathrm{m}^{2}$ moment of inertia of the total mass containing the rotor of the DC generator and the disc installed at the end of the shaft.

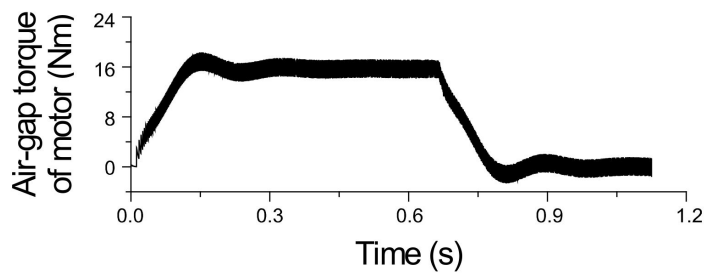

(a)

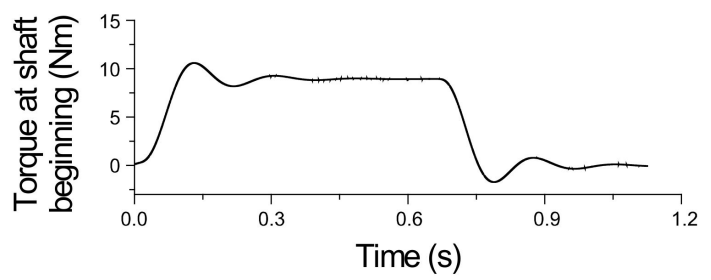

(b)

Figure 15. Waveforms of the air-gap torque (a) and the torque at the beginning of the shaft (b) during motor start-up in the system shown in Figure 7 for the $0.056 \mathrm{~kg} \cdot \mathrm{m}^{2}$ moment of inertia of the total mass containing the rotor of the DC generator and the disc installed at the end of the shaft.

In this case, the system behaves in a practically non-oscillatory manner. In Figure 16a, it can be observed that the slope of the waveform of the angular velocity reference at the output of the active torque limiter is practically constant during start-up, because such a small $\left(0.056 \mathrm{~kg} \cdot \mathrm{m}^{2}\right)$ moment of inertia of the total mass containing the rotor of the DC generator and the disc installed at the end of the shaft is not able to modify the predetermined value of this slope in practice. 


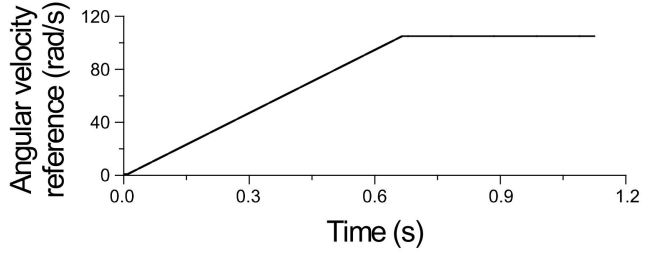

(a)

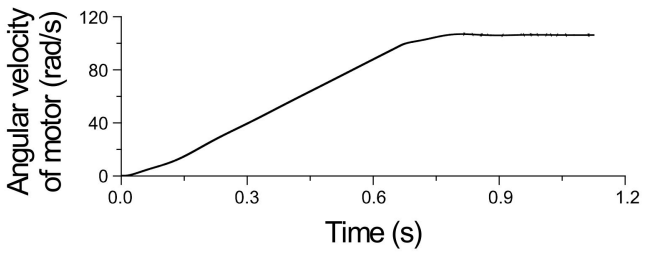

(b)

Figure 16. Waveforms of the angular velocity reference (a) and the angular velocity of the motor (b) during motor start-up in the system shown in Figure 7 for the $0.056 \mathrm{~kg} \cdot \mathrm{m}^{2}$ moment of inertia of the total mass containing the rotor of the DC generator and the disc installed at the end of the shaft.

Figure 17 shows the waveforms of the air-gap torque (a) and the torque at the beginning of the shaft (b), while Figure 18 shows the waveforms of the angular velocity reference and the angular velocity of the motor during start-up in the system shown in Figure 7 for the $1 \mathrm{~kg} \cdot \mathrm{m}^{2}$ moment of inertia of the total mass containing the rotor of the DC generator and the disc installed at the end of the shaft.

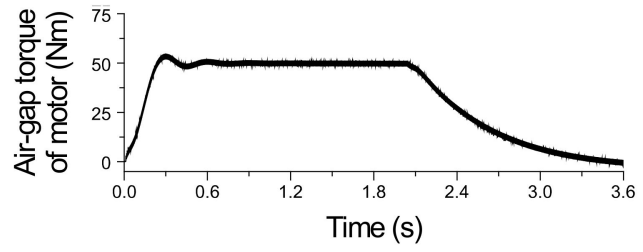

(a)

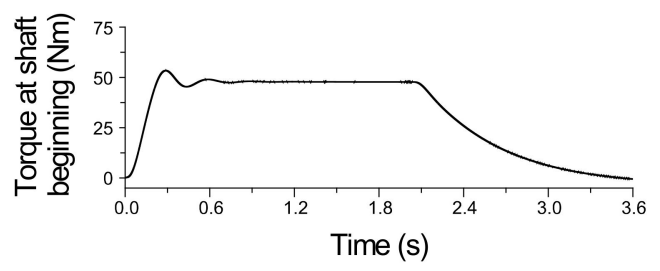

(b)

Figure 17. Waveforms of the air-gap torque (a) and the torque at the beginning of the shaft (b) during motor start-up in the system shown in Figure 7 for the $1 \mathrm{~kg} \cdot \mathrm{m}^{2}$ moment of inertia of the total mass containing the rotor of the DC generator and the disc installed at the end of the shaft.

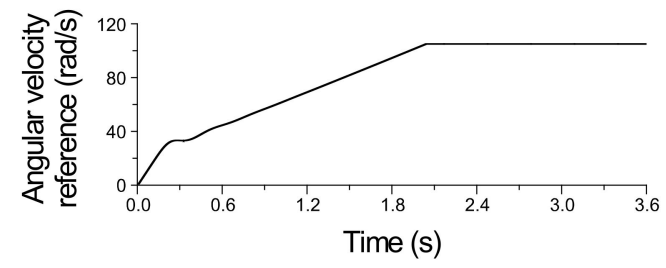

(a)

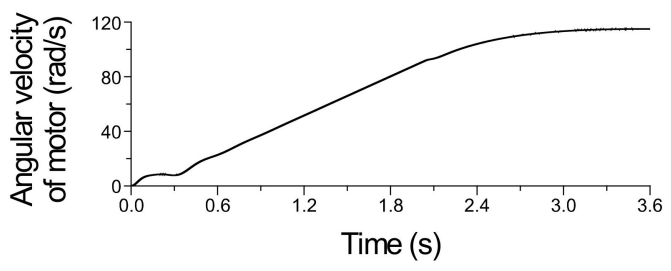

(b)

Figure 18. Waveforms of the angular velocity reference (a) and the angular velocity of the motor (b) during start-up in the system shown in Figure 7 for the $1 \mathrm{~kg} \cdot \mathrm{m}^{2}$ moment of inertia of the total mass containing the rotor of the DC generator and the disc installed at the end of the shaft.

In Figure 18a, it can be observed that, in contrast to the case illustrated in Figure 16a, the slope of the angular velocity reference during motor start-up is strongly modified by the output signal of the torque limit controller due to the significant value of the $1 \mathrm{~kg} \cdot \mathrm{m}^{2}$ moment of inertia of the total mass containing the rotor of the DC generator and the disc installed at the end of the shaft.

Note that the waveforms for the moment of inertia mentioned above, amounting to $0.056 \mathrm{~kg} \cdot \mathrm{m}^{2}$, are in the range of $0<\mathrm{t}<1.2 \mathrm{~s}$, whereas, for the moment of inertia amounting to $1 \mathrm{~kg} \cdot \mathrm{m}^{2}$, the waveforms are in the range of $0<\mathrm{t}<3.6 \mathrm{~s}$. Despite the visual similarity of the waveforms shown in both cases, the time needed to reach the steady state for the moment of inertia of $1 \mathrm{~kg} \cdot \mathrm{m}^{2}$ is about 3 times longer.

In the case of using an active torque limiter in the control system, no speed controller lock was found in any operating state of the system, so the mechanical torques or torsional moments as well as the angular velocities in the working mechanism are practically non- 
oscillating, i.e., with slight overshoots. Such an improvement in the dynamics of the system was achieved at the cost of slightly extending the start-up time and the reversal time.

\section{Conclusions}

Electromechanical systems consisting of electric drives, working machines, and mechanisms with long elastic couplings are characterized by complex dynamics that are defined by all system components. Mathematical modeling of such systems involves the formulation of mathematical models for each component of the system and combining these models into a whole. Particularly, complex mathematical descriptions may appear in the case of transmission shafts, i.e., long elastic elements that cannot be described using two-mass or three-mass lumped parameter models. For the mathematical description of transmission shafts, multi-mass models or models with distributed parameters can be used, and the latter approach has used in this study. As a result of the application of telegraphers' equations and solutions defined by d'Alembert, the transmission shaft was modeled analogously to the delay line known from acoustical engineering.

The dynamic behavior of electromechanical systems is significantly influenced by the electric motor control strategy, so the development of this strategy cannot be limited solely to the dynamics of the electric motor and the synthesis of its control, excluding other system components. The effect of such an approach would be leaving the phenomena occurring in the mechanism and the working machine beyond control in a situation where the dynamic behavior of this part of the system is significantly influenced by the torque produced by the motor, which, on the one hand, may cause an oscillating effect but may also contribute to the damping of oscillations, even if they occur as a result of the working machine.

The amplitude of the oscillation of torques and velocities in the mechanical system is influenced by the parameters of the transmission shaft, i.e., its length and diameter, and by the moments of inertia of the masses attached to it. As mentioned in the introduction, in real conditions, transmission shafts can reach even several meters. The reflection of such real conditions in the laboratory stand, equipped with shafts of relatively short length $(0.66 \mathrm{~m})$, was possible thanks to the selection of a small diameter for these shafts, e.g., $8 \mathrm{~mm}$.

The results presented in this paper show that, in order to effectively dampen the oscillations in the mechanical system, there is no need to use additional solutions in the field of electric motor control or additional damping devices, because this goal can be achieved by using a closed-loop speed control, which is already included in the control systems of the electric motor. A significant improvement in the dynamics of the entire electromechanical system can be achieved by ensuring the uninterrupted operation of the speed controller, i.e., by preventing its operation from being locked. In other words, the closed-loop speed control must be able to function efficiently in all operating states of the drive system. One way to do this is to slow down the speed reference change at the speed controller input. This slowing down should depend on the total moment of inertia of all rotating masses connected to the rotor of the electric motor, including the mass of the rotor itself. In such a situation, manually adjusting the rate of the speed reference change is not very effective, as it may lead either to an unnecessary extension of the settling time or to a locking of the speed controller. The solution proposed in this paper is to automate the process of adjusting the rate of the speed reference change by extending the standard motor speed control system with the uncomplicated structure of an active torque limiter. This structure ensures the uninterrupted operation of the speed controller in all operating states of the drive system, which is confirmed by the presented results. Thanks to this solution, the oscillations in the mechanical system are not only quickly damped, but these oscillations practically disappear and are reduced to slight overshoots appearing in the waveforms of the torques and moments in the mechanical system. The presented waveforms show that the amplitude of these overshoots depends on the moment of inertia of the rotating masses connected to the rotor of the motor. This is obvious because the parameters of the plant (process) change. The solution that eliminates the influence of the 
moment of inertia on the overshoot amplitude involves equipping the active torque limiter with an adaptive structure, but that would be associated with a significant expansion of the entire limiter structure.

The type of torque limit controller included in the active torque limiter also influences the amplitude of the overshoot. After selecting a static controller, the dynamics of the system were compared with regard to the linear and non-linear transition function used in this controller, and improved properties were found in the non-linear controller. Due to the simplicity of a practical implementation, a transition function proportional to the fifth power of the motor torque was used. Similar results (not presented in the paper) were obtained using the function proportional to the third power of the motor torque. The use of only odd functions results from the necessity to obtain both their positive and negative values.

Author Contributions: Conceptualization, A.P.; methodology, A.P., A.S. and A.C.; software, A.P. and A.C.; validation, A.P., A.S. and A.C.; formal analysis, A.S. and A.C.; investigation, A.P., A.S. and A.C.; writing-original draft preparation, A.P., A.S. and A.C.; writing-review and editing, A.S. and A.C.; visualization, A.S. and A.C.; supervision, A.P. and A.C.; project administration, A.S. All authors have read and agreed to the published version of the manuscript.

Funding: This research received no external funding.

Institutional Review Board Statement: Not applicable.

Informed Consent Statement: Informed consent was obtained from all subjects involved in the study.

Data Availability Statement: Data is contained within the article.

Conflicts of Interest: The authors declare that there are no conflict of interest.

\section{References}

1. Rabb, S.F.; Kahnamouei, J.T.; Liang, X.; Yang, J. Shaft Failure Analysis in Soft-Starter Fed Electrical Submersible Pump Systems. IEEE Open J. Ind. Appl. 2020, 1, 1-10. [CrossRef]

2. Ekemb, G.; Slaoui-Hasnaoui, F.; Song-Manguelle, J.; Lingom, P.M.; Fofana, I. Instantaneous electromagnetic torque components in synchronous motors fed by load-commutated inverters. Energies 2021, 14, 3223. [CrossRef]

3. Dong, X.; Wang, C.; Yang, Q.; Si, W. System identification of distributed parameter system with recurrent trajectory via deterministic learning and interpolation. Nonlinear Dyn. 2019, 95, 73-86. [CrossRef]

4. Lozynskyy, A.; Chaban, A.; Perzyński, T.; Szafraniec, A.; Kasha, L. Application of fractional-order calculus to improve the mathematical model of a two-mass system with a long shaft. Energies 2021, 14, 1854. [CrossRef]

5. Łukasik, Z.; Czaban, A.; Szafraniec, A.; Żuk, V. The mathematical model of the drive system with asynchronous motor and vertical pump. Przeglad Elektrotechniczny 2018, 1, 133-138. [CrossRef]

6. Popenda, A. Mathematical modelling of transmission shafts based on electrical and mechanical similarities. Przeglad Elektrotechniczny 2019, 12, 196-199. [CrossRef]

7. Peng, R.; Zhang, X.; Shi, P. Vertical-horizontal coupling vibration of hot rolling mill rolls under multi-piecewise nonlinear constraints. Metals 2021, 11, 170. [CrossRef]

8. Fan, X.B.; Zang, Y.; Jin, K. Rolling process and its influence analysis on hot continuous rolling mill vibration. Appl. Phys. A 2016, 122, 1008. [CrossRef]

9. Ramírez, G.A.; Valenzuela, M.A.; Pittman, S.; Lorenz, R.D. Modeling and Evaluation of Paper Machine Coater Sections Part 1: 1-Coater Section and Tension Setpoints. IEEE Trans. Ind. Appl. 2019, 55, 2144-2154. [CrossRef]

10. Song, M.-H.; Pham, X.D.; Vuong, Q.D. Torsional vibration stress and fatigue strength analysis of marine propulsion shafting system based on engine operation patterns. J. Mar. Sci. Eng. 2020, 8, 613. [CrossRef]

11. Zhang, M.; Zhang, G.H.; Liu, Z.S. Research on large ship propulsion shafting alignment multi-nonlinear-elastic support model. J. Ship Mech. 2016, 1, 176-183.

12. Jee, J.; Kim, C.; Kim, Y. Design improvement of a viscous-spring damper for controlling torsional vibration in a propulsion shafting system with an engine acceleration problem. J. Mar. Sci. Eng. 2020, 8, 428. [CrossRef]

13. Chaban, A.; Lis, M.; Szafraniec, A.; Jedynak, R. Application of genetic algorithm elements to modelling of rotation processes in motion transmission including a long shaft. Energies 2021, 14, 115. [CrossRef]

14. Czaban, A.; Lis, M. Mathematical model of an electromechanical system with a long elastic element (in Polish). Prz. Elektrotech. 2012, 12, 167-170. 
15. Szabat, K.; Orłowska-Kowalska, T. Application of the Kalman filters to the high-performance drive system with elastic coupling. IEEE Trans. Ind. Electron. 2012, 11, 4226-4235. [CrossRef]

16. Serkies, P.; Szabat, K. Application of the MPC controller to the Position Control of the Two-Mass Drive System. IEEE Trans. Ind. Electron. 2013, 9, 3679-3688. [CrossRef]

17. Chaban, A.; Łukasik, Z.; Popenda, A.; Szafraniec, A. Mathematical Modelling of Transient Processes in an Asynchronous Drive with a Long Shaft Including Cardan Joints. Energies 2021, 14, 5692. [CrossRef]

18. O'Sullivan, T.; Bingham, C.C.; Schofield, N. High-performance control of dual-inertia servo-drive systems using low-cost integrated SAW torque transducers. IEEE Trans. Ind. Electron. 2006, 4, 1226-1237. [CrossRef]

19. Li, W.; Hori, Y. Vibration suppression using single neuron-based PI fuzzy controller and fractional-order disturbance observer. IEEE Trans. Ind. Electron. 2007, 1, 117-126. [CrossRef]

20. Valenzuela, M.A.; Bentley, J.M.; Lorenz, R.D. Evaluation of torsional oscillations in paper machine sections. IEEE Trans. Ind. Electron. 2005, 2, 493-501. [CrossRef]

21. Popenda, A.; Lis, M.; Nowak, M.; Blecharz, K. Mathematical Modelling of Drive System with an Elastic Coupling Based on Formal Analogy between the Transmission Shaft and the Electric Transmission Line. Energies 2020, 13, 1181. [CrossRef]

22. Pielorz, A. Dynamic analysis of torsional discrete-continuous systems with position-dependent variable inertia. J. Theor. Appl. Mech. 2014, 1, 107-115.

23. Grzadziela, A. Modelling of propeller shaft dynamics at pulse load. Pol. Marit. Res. 2008, 4, 52-58. [CrossRef]

24. Jinli, X.; Xingyi, S.; Bo, P. Numerical Analysis and Demonstration: Transmission Shaft Influence on Meshing Vibration in Driving and Driven Gears. Hindawi Publ. Corp. Shock Vib. Vol. 2015, 10, 1-10. [CrossRef]

25. Swanson, D.C. Signal Processing for Intelligent Sensor Systems with MATLAB®, 2nd ed.; CRC Press: Abingdon, UK, $2017 ;$ pp. 7-23.

26. Łuczak, D. Mathematical model of multi-mass electric drive system with flexible connection. In Proceedings of the 19th International Conference on Methods and Models in Automation and Robotics (MMAR), Miedzyzdroje, Poland, 2-5 September 2014; IEEE: Piscataway, NJ, USA, 2014; pp. 290-295. [CrossRef]

27. Muyeen, S.M.; Mohd, H.A.; Takahashi, R.; Murata, T.; Tamura, J.; Tomaki, Y.; Sakahara, A.; Sasano, E. Transient Stability Analysis of Wind Generator System with the Consideration of Multi-Mass Shaft Model. In Proceedings of the International Conference on Power Electronics and Drive Systems, Kuala Lumpur, Malaysia, 28 November-1 December 2005; IEEE: Piscataway, NJ, USA, 2006. [CrossRef]

28. Saarakkala, S.; Hinkkanen, M. Identification of Two-Mass Mechanical Systems Using Torque Excitation: Design and Experimental Evaluation. IEEE Trans. Ind. Appl. 2015, 51, 4180-4189. [CrossRef]

29. Kabziński, J.; Mosiołek, P. Adaptive, nonlinear state transformation-based control of motion in presence of hard constraints. Bull. Pol. Acad. Sci. Tech. Sci. 2020, 68, 963-971.

30. Lee, D.; Lee, J.H.; Ahn, J. Mechanical vibration reduction control of two-mass permanent magnet synchronous motor using adaptive notch filter with fast Fourier transform analysis. IET Electr. Power Appl. 2012, 6, 455-461. [CrossRef]

31. Kabziński, J.; Mosiołek, P.; Jastrzębski, M. Adaptive position tracking with hard constraints—barrier lyapunov functions approach. Stud. Syst. Decis. Control 2017, 75, 27-52.

32. Szabat, K.; Orlowska-Kowalska, T. Vibration suppression in a two-mass drive system using PI speed controller and additional feedbacks-Comparative study. IEEE Trans. Ind. Electron. 2007, 54, 1193-1206. [CrossRef]

33. Kabziński, J.; Mosiołek, P. Integrated, Multi-Approach, Adaptive Control of Two-Mass Drive with Nonlinear Damping and Stiffness. Energies 2021, 14, 5475. [CrossRef]

34. Xu, S.; Sun, G.; Cheng, Z. Fractional order modeling and residual vibration suppression for flexible two-mass system. In Proceedings of the 2017 29th Chinese Control and Decision Conference (CCDC), Chongqing, China, 28-30 May 2017; pp. 3658-3664.

35. Popenda, A. Model-simulation investigations of induction motor with the consideration of skin effect in rotor bars. Przeglad Elektrotechniczny 2012, 12, 29-31.

36. Takahashi, I.; Noguchi, T. A New Quick-Response and High-Efficiency Control Strategy of an Induction Motor. IEEE Trans. Ind. Appl. 1986, 5, 820-827. [CrossRef] 